
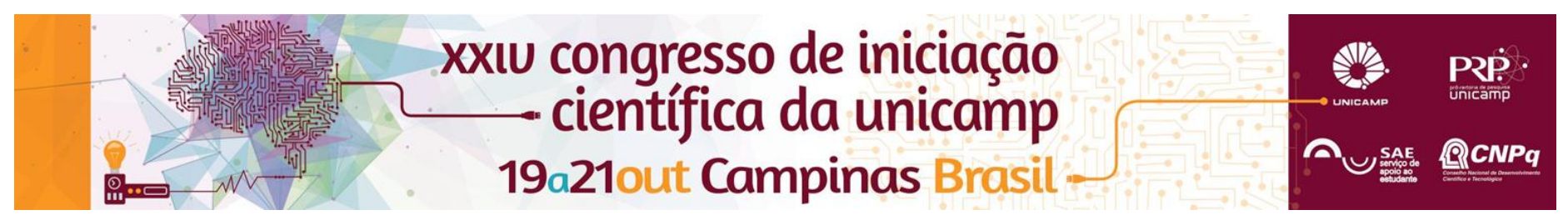

\title{
Estudo Retrospectivo de Lesões Pediátricas Orais Diagnosticadas na FOP- Unicamp
}

\author{
Aline P. Ataíde*, Pablo A. Vargas, Felipe P. Fonseca
}

\section{Resumo}

Lesões orais e maxilofaciais afetando crianças são relativamente incomuns nos centros diagnósticos, contabilizando aproximadamente $10 \%$ de todas as amostras analisadas. Estudos que investigam essas lesões pediátricas em diferentes áreas geográficas são muito desejados por patologistas orais e pediatras para melhorar as habilidades de diagnóstico. $\mathrm{O}$ alvo deste estudo é determinar se existe uma importante diferença na incidência de lesões orais na população do sudeste brasileiro em comparação a outras regiões brasileiras e do globo. Os arquivos da divisão de patologia oral da Universidade de Campinas foram revistos retrospectivamente todos os casos afetando pacientes de 16 anos e jovens, diagnosticados de 2000 a 2014. Nossos resultados foram similares à aqueles descritos na literatura.

\section{Palavras-chave:}

Pediatria, lesões orais, glândulas salivares

\section{Introdução}

Lesões orais que afetam pacientes pediátricos representam aproximadamente $10 \%$ da quantidade total de leões diagnosticadas em centros especializados.

No Brasil poucas séries que descrevem a incidência de leões orais em pacientes pediátricos tiveram dados publicados (Souza et al., 2003; Lima et al., 2008; Vale et al., 2013; Martins-Filho et al., 2015; Pessoa et al., 2015) Portanto, neste estudo foi investigada a distribuição de lesões bucais que afetam pacientes pediátricos recuperados de um centro de referência em patologia oral, localizado na região sudeste do Brasil, com a finalidade de determinar se há alguma diferença na incidência destas lesões quando comparado com outros regiões brasileiras e com outras regiões do globo.

\section{Resultados e Discussão}

No período investigado de 15 anos, 34138 lesões foram diagnosticadas sendo 2539 de pacientes afetados com 16 anos ou mais jovens representando $7,4 \%$ de todas as espécies recebidas no departamento.

Foi encontrada uma leve predominância feminina (1416 vs 1123 dos casos) com uma relação em homem:mulher de 0,79 . Foi observado que paciente de 13 a 16 anos foram mais afetados (39.6\%), pacientes (0-4 constituíram $3.6 \%$, 5-8 constituíram 20.6\%, 9-12 constituíram 36.2\% da amostra). A proporção de lesões nos principais grupos de patologias foi semelhante a observada em outros estudos, com a exceção dos grupos salivar gland disease e dental pathology (Fig. 1B). As lesões mais frequentemente observadas também foram as mais frequentes em estudos anteriores realizados no Brasil (Fig. 1B).

\section{Conclusão}

A compreensão dos padrões, a frequência e a distribuição de lesões orais pediátricas melhora o algorítimo de diagnóstico para patologistas orais e pediatras e este estudo demonstrou que a distribuição das lesões orais é muito semelhante em diferentes regiões do globo.
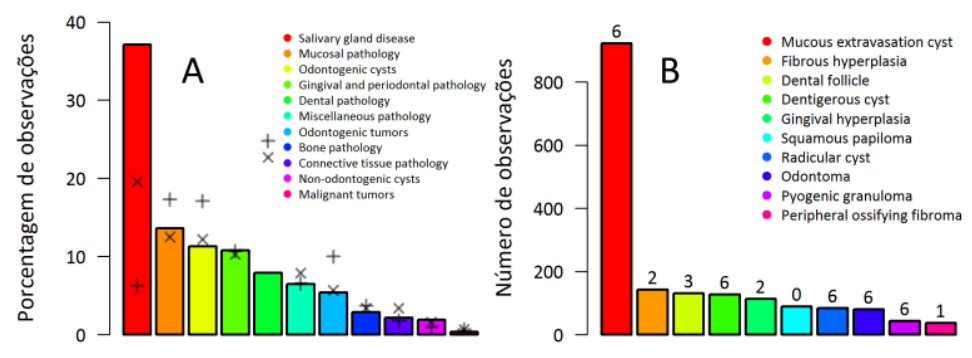

Figura 1. A: porcentagem de lesões observadas por grupos; +: porcentagem observada por (Ha et al., 2014); x porcentagem observada por (Jones et al., 2006). B: número de observações nas dez lesões mais frequentes. Números acima das barras representam número de estudos brasileiros em que essa lesão esteve entre as dez mais comuns, o total de estudos consultados foi de 6.

\section{Agradecimentos}

Agradeço ao meu orientador, co-orientador e a $\mathrm{PIBIC/CNPQ}$ pelo fomento à pesquisa

\footnotetext{
${ }^{1}$ Jones AV, Franklin CD. An analysis of oral and maxillofacial pathology found in children over a 30-year period. Int J Paediatr Dent 2006; 16: 19-30.

${ }^{2}$ Lima SG, Fontes ST, de Araujo LM, Etges A, Tarquinio SB, Gomes AP. A survey of oral and maxillofacial biopsies in children: a single-center retrospective study of 20 years in Pelotas Brazil. J Appl Oral Sci 2008; 16: 397-402.

${ }^{3}$ Zuñiga MD, Méndez CR, Kauterich RR, Paniagua DC. Paediatric oral pathology in a Chilean population: a 15-year review. Int J Paed Dent 2013; 23 : 346-351.

${ }^{4}$ Brierley DJ, Chee CKM, Speight PM. A review of paediatric oral and maxillofacial pathology. Int J Paed Dent 2013; 23: 319-329
}

${ }^{5}$ Ha WN, Kelloway E, Dost F, Farah CS. A retrospective analysis of oral and maxillofacial pathology in an Australian paediatric population. Aust Dent J 2014; 59: 221-225.

\footnotetext{
${ }^{6}$ Cavalcante RB, Turatti E, Daniel APB, Alencar GF, Chen Z. Retrospective review of oral and maxillofacial pathology in a Brazilian paediatric population. Eur Arch Paediatr Dent 2016; 17:115-122.
} 